\title{
A Plasma Anti-Contaminator for Imbedded Applications in SEMs and FIBs
}

\author{
Ronald Vane and Vincent Carlino
}

XEI Scientific, 3124 Wessex Way, Redwood City, CA 94061

XEI Scientific invented a practical plasma anticontamination system for Scanning Electron Microscopes (SEMs) in 1999 [1]. Now called the Evactron ${ }^{\circledR}$ Anti-Contaminator, this system has been found to quickly and effectively remove hydrocarbons from both EM chambers and specimens. By removing hydrocarbons, contamination artifacts such as black squares and scan deposits are prevented and controlled. The Evactron unit uses a unique plasma generator to create a low temperature RF plasma in a low vacuum that is able to make oxygen radicals from air. These radicals (oxygen atoms) gently ash hydrocarbons in the vacuum chamber to form $\mathrm{CO}$ and $\mathrm{H} 2 \mathrm{O}$ gases that are removed by viscous flow to the vacuum pump.

Hydrocarbon contamination causes measurement errors in high resolution FESEM, CD SEM \& TEM due to deposits laid down by the electron beam. Narrow line width and small feature sizes demand the lowest contamination levels for analytical laboratory applications and on production and inspection floors. The demands of semiconductor production and inspection require that SEMs and FIBs (Focused Ion Beam) instruments operate cleaner than in the past in order to image and measure sub $100 \mathrm{~nm}$ features. Chamber residue on surfaces, components and traces residing on specimens are all sources of hydrocarbons that are polymerized by the electron beam on scanned areas causing image blurring and resolution lose. Periodic Evactron Anti-contaminator plasma cleaning has been proven to be effective for controlling these hydrocarbons [2],[3].

The original Evactron design used a simple manually operated micro needle valve as a metering valve for the air entering the plasma to make the oxygen radicals. Used with a constant rotational speed vacuum pump such as a rotary vane pump, the pressure was easily adjusted only once when the system was installed. When open, the leak valve and roughing pump always come to the same equilibrium pressure. Newer EM evacuation system designs use a turbo pump that accelerates during pump down. The manual valve is unable to maintain a constant pressure against the changing pump speed, and constant adjustment is needed.

A new Evactron system was needed that could be imbedded or built into electron microscope and FIB tools and operate in the background with little attention from the operator or maintenance technician. Such a system needed to be rack mounted, be controlled and monitored by a computer and be factory set to maintain the correct RF power and vacuum level for optimum cleaning no matter what the pumping speed. Removing the manually operated metering valve was the first goal of the new design. An electrically controlled variable solenoid valve was identified that had the operating characteristic desired. The valve opened in proportion to the $0-24 \mathrm{VDC}$ signal provided it, and this valve produced the desired leak rate in the middle of it operating range. A feed back circuit from a modular Pirani gauge with an analog voltage output supplies the required feed back to adjust the valve to maintain the required pressure. A circuit was devised that would adjust the voltage and operate the valve to maintain constant pressure during cleaning. It also compensated for increasing pump speed thermal drift of the valve opening. Similar circuit is used to control RF power output. Vacuum level and RF power are adjusted with screwdriver adjusted trim pots that are factory set to 
the optimum levels for plasma cleaning. A power readout and vacuum level readout are available on meter for system monitoring and adjustment by service personal. Normally these are never adjusted by the user. The controller is mounted in a rack mounted (3.5" $\mathrm{H} \mathrm{x} \mathrm{19"} \mathrm{W)} \mathrm{controller} \mathrm{for} \mathrm{placement} \mathrm{in}$ the equipment racks of the charged beam tool. Output and input connectors on the rear panel allow monitoring and control of the plasma cleaning operation by a computer or a testing box.

The new design Evactron Anti-Contaminator has proven to be useful for both routine and non-routine hydrocarbon removal in SEMs and FIBs. It is controlled from the control computer of the tool so that it can be programmed to clean either on a routine basis or as a maintenance procedure as needed. It allows chambers to be cleaned after vacuum accidents and poor vacuum practice events without hours of disassembly and manual cleaning. In routine use the system can be used regularly to clean every specimen brought into the chamber in one or two minutes or as a routine chamber maintenance procedure for 5-10 minutes when the tool is idle.

References:

[1] Ronald A. Vane, US Patents 6,105,589 (issued Aug. 2000) and 6,452,315 (issued Sept. 2002)

[2] András E. Vladár et al "Active Monitoring and Control of Electron Beam Induced

Contamination” Proc. SPIE Vol. 4344 (2001), 835.

[3] Neal Sullivan et al "Study of the Effectiveness of the Removal of Hydrocarbon Contamination by Oxidative Cleaning inside the SEM" Proc. of Microscopy and Microanalysis 2002, 720CD

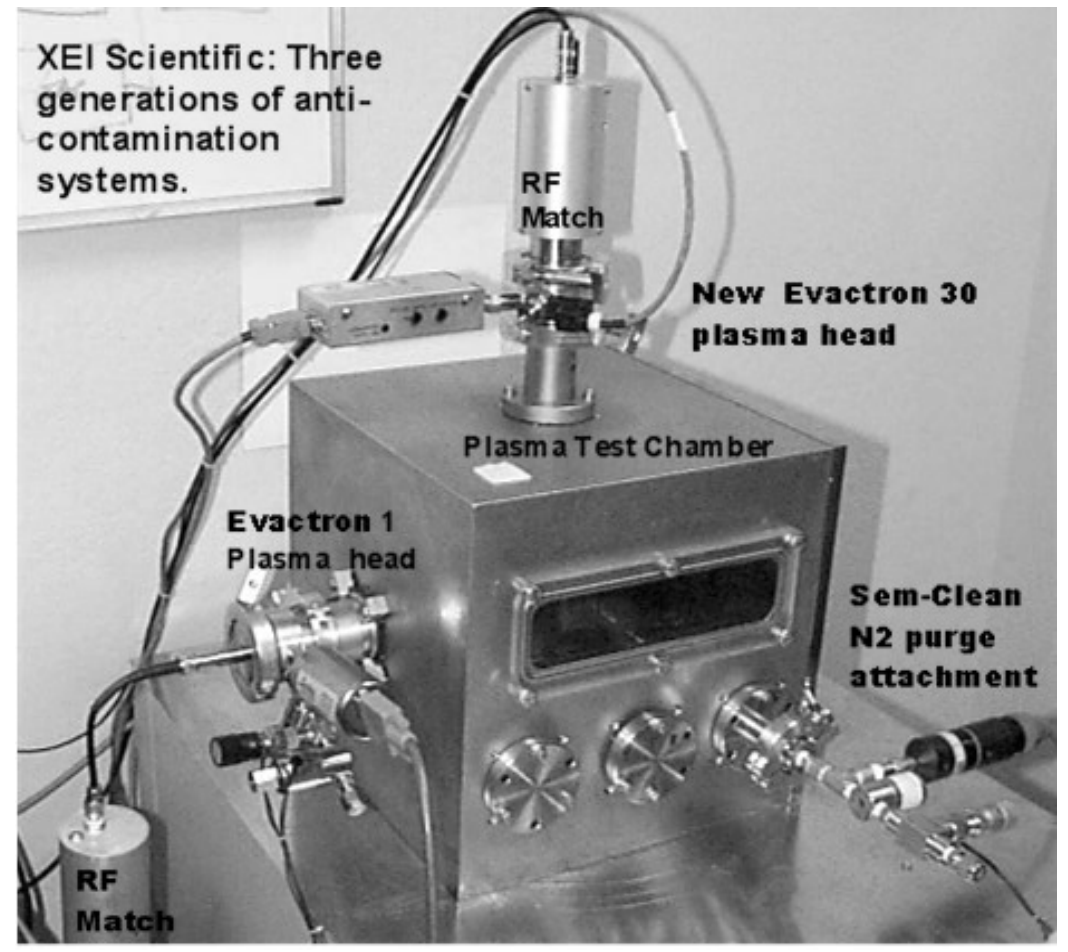

Figure 1: A photograph showing both the new design plasma head of the Evactron 30 system (top) compared to the original design Evactron 1 plasma head (side) with separate RF match circuit on a test chamber. The plasma head on the new design system has the RF impedance matching circuit mounted onto the RF power feed through. The variable solenoid valve replaces both the manual metering valve and solenoid ON/OFF valve of the Evactron 1 model. 